\title{
Comparative evaluation of biopolymers and synthetic polymers as hydroxyapatite dispersants for industrial water systems
}

\author{
Z. Amjad,* A. Kweik and K. Bickett \\ School of Arts and Sciences, Walsh University, 2020 E. Maple Street, N. Canton, \\ OH 44720, USA \\ *E-mail:zamjad@walsh.edu
}

\begin{abstract}
The dispersion of hydroxyapatite, $\mathrm{Ca}_{5}\left(\mathrm{PO}_{4}\right)_{3} \mathrm{OH}$, HAP, by a variety of biopolymers and synthetic polymers of different composition and ionic charge has been investigated. The dispersion data show that polymer effectiveness as HAP dispersant strongly depends upon polymer architecture. Results also reveal that synthetic polymers perform better than biopolymers. It has been found that anionic, non-ionic, amphoteric, and cationic surfactants are ineffective as HAP dispersants. Additionally, it has also been observed that cationic surfactant and cationic polymer exhibit antagonistic effect on the performance of anionic polymeric dispersants.
\end{abstract}

Keywords: hydroxyapatite, dispersion, biopolymers, synthetic polymer surfactants.

Received: July 28, 2015

doi: $\underline{10.17675 / 2305-6894-2015-4-3-269-283}$

\section{Introduction}

Calcium phosphate scale in industrial water system results from the presence of orthophosphate in the circulating water. The main source for phosphate in the circulating water is its use as a chemical treatment to prevent corrosion on low carbon steel water pipes and heat exchanger equipment. To prevent calcium phosphate scale formation, the use of calcium phosphate inhibitor is required when using this type of corrosion control. The solution chemistry of calcium phosphate is very complex. It is often assumed that thermodynamically most stable hydroxyapatite $\left(\mathrm{Ca}_{5}\left(\mathrm{PO}_{4}\right)_{3} \mathrm{OH}, \mathrm{HAP}\right)$ is a suitable prototype for scale prediction. However, it is generally accepted that other phases such as amorphous calcium phosphate $\left(\mathrm{Ca}_{3}\left(\mathrm{PO}_{4}\right)_{2}, \mathrm{ACP}\right)$, dicalcium phosphate dihydrate $\left(\mathrm{CaHPO}_{4} \cdot 2 \mathrm{H}_{2} \mathrm{O}, \mathrm{DCPD}\right)$, and octacalcium phosphate $\left(\mathrm{Ca}_{8} \mathrm{H}_{2}\left(\mathrm{PO}_{4}\right)_{6} \cdot 5 \mathrm{H}_{2} \mathrm{O}, \mathrm{OCP}\right)$ may also be formed. In high temperature application such as boiler HAP is formed on the boiler surface. HAP is also the major inorganic component of teeth. In addition, calcium phosphates are widely produced in industry, in such forms as, ceramics, nutrient supplements, medicine, dentrifices, and stabilizers for plastic. They are utilized in solid state chemistry as fluorescent lamp phosphors and play a role in waste water treatment processes. Dental tartar is a calcareous deposit on teeth consisting primarily of calcium phosphates and other calcium magnesium salts [1]. 
The suspended matter typically present in feed water includes clay, minerals, metal oxides, metal phosphate, algae, bacteria, and viruses. The solid concentration usually ranges from $<5 \mathrm{mg} / \mathrm{L}$ to $>300 \mathrm{mg} / \mathrm{L}$, and in some cases, especially during floods, may go up to $>500,000$ [2]. The metal oxides, phosphate, and carbonates present in water may include corrosion products (i.e., $\mathrm{Fe}_{2} \mathrm{O}_{3}, \mathrm{Fe}_{3} \mathrm{O}_{4}$ ), $\mathrm{SiO}_{2}$, calcium phosphate, and calcium carbonate. If not properly treated, deposition of suspended matter on equipment surfaces leads to decreased heat transfer, increased operational costs, and in some cases premature replacement of expensive equipment.

During the last three decades, suspension of calcium phosphates, clays, metal oxides, calcium carbonate, pigments, ceramic materials, and other insoluble inorganic particulate solids in aqueous systems through the use of small quantities of synthetic polymeric and non-polymeric additives has become an increasingly important area of study with high technological relevance. The effectiveness of polymers as dispersants for clay, calcium phosphate, silica, magnesium silicate, and iron oxide has been investigated by several researchers. Results of these studies reveal that polymers containing different functional groups i.e., carboxyl, sulfonic, amide, ester, etc., exhibit good to excellent dispersancy activity $[3,4,5]$. Dubin [6] in his study on the evaluation of polyphosphates, phosphonates, and homopolymers of acrylic acid, maleic acid, and acrylic/maleic acid-based copolymers as dispersants for iron oxide showed that copolymers performed better than polyphosphates and phosphonates. Zuhl et al. [7] reported that acrylic acid based terpolymers performed better than homoacrylic acids as hydroxyapatite dispersants.

Surfactants form a unique class of compounds that are used in a variety of applications including laundry detergents, dish washing liquids, agrochemicals, pharmaceuticals, petroleum, mineral ores, personal care, floor cleaners, paints, coatings, fuel additives, and photographic films. In desalination of sea/brackish waters by reverse osmosis (RO) process, deposition of unwanted materials on RO membrane surfaces is a common occurrence. Surfactants are commonly incorporated into cleaner formulations to remove deposits from RO membrane surfaces.

Surfactants are generally classified into four groups: $(a)$ anionic, $(b)$ non-ionic, $(c)$ amphoteric, and $(d)$ cationic. In laundry detergents, surfactants are used to aid in the removal of oily soil and in the suspension of solids in a washing liquid. In hard water (water containing multivalent cations), anionic surfactants tend to form insoluble salts with metal ions, and then they are no longer available to participate in the cleaning process. Cationic surfactants are generally used in textile as a fabric softener. The interactions of cationic surfactants with anionic surfactants have been investigated. Results of this study show that anionic surfactants such as sodium dodecyl sulfate and sodium octylbenzene sulfonate form insoluble salts with calcium ions in aqueous solutions [8]. In another study on the compatibility of anionic surfactants with cationic surfactants, it was shown that using the phase diagram it is possible to formulate homogeneous and stable compositions 
[9]. In a recent contributions from our laboratories we presented results on the impact of surfactants in preventing the precipitation of calcium phosphate by anionic polymers [10].

The present study is focused on the evaluation of bio- and synthetic polymers as HAP dispersants for aqueous systems. The polymers tested include: bio-polymers i.e., carboxymethyl inulin with different degree of carboxylation and lignosulfonates, and synthetic polymers i.e., homo- and copolymers of acrylic acid and maleic acid containing different functional groups. Additionally, the influence of a variety of surfactants containing different charges has been investigated as dispersants for HAP and in combination with polymers. The results presented in this paper help explain why a specific polymer does not perform as expected, and how polymer dosage can be adjusted to achieve optimum performance.

\section{Experimental}

Grade A glassware and reagent grade chemicals were used. Hydroxyapatite used in the present study was obtained from Aldrich, USA, and was characterized by X-ray diffraction and chemical analysis. The polymeric materials and surfactants used as dispersants were selected from commercial materials. All dispersant solutions were prepared on a dry weight basis. The desired concentrations were obtained by dilution. Table 1 lists the polymers and surfactants tested in the present study.

Table 1. List of polymers and surfactants tested.

\begin{tabular}{cccc}
\hline Additive & Ionic charge $^{a}$ & Mol. Wt & Acronym \\
\hline Poly(acrylic acid) & negative & $3 \mathrm{k}$ & PA \\
Poly(acrylic acid) & negative & $60 \mathrm{k}$ & PA1 \\
Poly(acrylic acid) & negative & $200 \mathrm{k}$ & PA2 \\
Poly(methacrylic acid) & negative & $6 \mathrm{k}$ & PMA \\
Poly(maleic acid) & negative & $<1 \mathrm{k}$ & PM \\
Poly(aspartic acid) & negative & $<6 \mathrm{k}$ & PAS \\
Poly(vinyl pyrrolidone) & neutral & $<10 \mathrm{k}$ & PVP \\
Poly(diallyldimethyl ammonium chloride) & positive & $<10 \mathrm{k}$ & PDA \\
Poly(acrylic acid:2-methyl-2-acrylamido-2-methyl & negative & $<10 \mathrm{k}$ & PSS \\
propane sulfonic acid: sulfonated styrene) & negative & 288 & SLS \\
Sodium lauryl sulfate & negative & 208 & SXS \\
Sodium xylene sulfonate & negative/positive & 342 & CAPB \\
Cocoamidopropyl betaine & neutral & 647 & OCP \\
Octyl phenol ethoxylate & positive & 320 & CTAC \\
Cetyltrimethylammonium chloride & &
\end{tabular}

${ }^{a} \mathrm{pH}$ of working solution. 
Dispersancy Protocol: The dispersancy experiments were run in $100 \mathrm{~mL}$ graduated cylinders and at room temperature $\left(\sim 23^{\circ} \mathrm{C}\right)$. The HAP dispersion test was conducted by adding $0.300 \mathrm{~g}$ of HAP to known volume of synthetic water containing varying amount of dispersant (surfactants and/or polymers). After the addition of HAP, cylinders were covered with Parafilm and manually mixed with a motion similar to repeatedly turning over an hourglass for 1 minute and left to stand. The synthetic water contained calcium chloride, magnesium chloride, sodium chloride, sodium sulfate and sodium bicarbonate. The experimental solution in the cylinder totaled $100 \mathrm{~mL}$ and was comprised of varying dosage (0 to $10 \mathrm{ppm}$ ) of dispersant, $0.300 \mathrm{~g} \mathrm{HAP}, 106 \mathrm{mg} / \mathrm{L} \mathrm{Ca}, 31 \mathrm{mg} / \mathrm{L} \mathrm{Mg}, 246 \mathrm{mg} / \mathrm{L}$ $\mathrm{Na}, 329 \mathrm{mg} / \mathrm{L} \mathrm{Cl}, 202 \mathrm{mg} / \mathrm{L}$ sulfate, and $62 \mathrm{mg} / \mathrm{L}$ bicarbonate.

A standard experiment consisted of six tests running simultaneously in six cylinders. At known intervals transmittance $(\% T)$ readings were taken using a Brinkmann ${ }^{\circledR}$ Probe Colorimeter equipped with a $420 \mathrm{~nm}$ filter. Results from these experiments have shown good reproducibility within $\pm 6 \%$. Dispersion $(\% D)$ was calculated from $\% T$ readings as a function of HAP dispersed compared to control (no dispersant). Therefore, greater dispersion was indicated by lower $\% T$ or greater $\% D$. The $\% D$ was calculated using the following equation:

$$
\% \text { Dispersion }(\% D)=[100-\{\% T \times(1 / 80) \times 100\}]
$$

\section{Results and Discussion}

Dispersants belong to a class of additives that contains both natural and synthetic materials containing non-ionic charge monomers e.g., acrylamide $\left(-\mathrm{CONH}_{2}\right)$, ester, $(-\mathrm{COOR})$ and anionic charge functional groups, e.g., carboxyl $(-\mathrm{COOH})$, sulfonic acid $\left(-\mathrm{SO}_{3} \mathrm{H}\right)$. The dispersants function by adsorbing onto the negatively charged suspended particles. During the process, the particles are coated with the dispersant, resulting in an increased negative charge that causes the particles to repel each other and remain suspended in an aqueous stream. The molecular weight (MW) of the dispersant is important in order to prevent bridging, which could occur with high MW polymers. In addition, dispersants can remove existing deposits (e.g., corrosion products, precipitated mineral salts, etc.) by deagglomeration of large particles.

The dispersants evaluated in this study fall into four categories: $(a)$ carboxymethyl inulin (CMI), lignosulfonate (LS), (b) homopolymers of acrylic acid, maleic acid, aspartic acid, methacrylic acid, vinylpyrolidone, terpolymer containing monomers with different functional groups, (c), cationic polymer such as poly(diallyldimethyl ammonium chloride), and $(d)$ surfactants containing different functional groups. 


\section{Performance of Biopolymers}

Recently, there has been an increasing interest in the development and applications of biodegradable and environmentally friendly biopolymers. CMI is a chemical derivative produced by carboxymethylation of inulin, a polysaccharide-based polymer present in the roots of chicory plant. The performance of CMI as inhibitors for calcium carbonate, calcium oxalate, and barium sulfate has been reported $[11,12,13]$. Results of these studies reveal that $\mathrm{CMI}$ is an effective inhibitor for various scales and the effectiveness of inhibitor depends on the degree of carboxylation. Amjad and Goubert evaluated the performance of CMI as an iron oxide dispersants. The results show that biopolymers perform well in comparison with currently used homopolymers of acrylic acid (AA) but not as effective as AA-based terpolymers [14].

Figure 1 presents $\%$ transmittance $(\% T)$ data collected as a function of time and in the absence and presence and varying dosages of CMI-25. There are two points worth noting: (a) $\% T$ value increases with increasing time reflecting settling of HAP particles, and $(b)$ $\% T$ decreases with increasing CMI-25 dosages. For example, $\% T$ values obtained in the presence of $1.0 \mathrm{ppm}$ and $2.50 \mathrm{ppm}$ at $3 \mathrm{hr}$ are $82 \%$ and $76 \%$ respectively, compared to $87 \%$ obtained in the absence of CMI-25. As shown in Figure 1, increasing the CMI-25 concentration twofold, i.e., from $5 \mathrm{ppm}$ to $10 \mathrm{ppm}$, results in further decrease in $\% T$ value, suggesting more adsorption of dispersant with increasing concentration. Figure 1 also shows that increasing the HAP-dispersant contact time from $3 \mathrm{hr}$ to $4 \mathrm{hr}$ does not show any significant effect on $\% T$ values in the absence and presence of dispersant. Based on these observations, we chose $3 \mathrm{hr}$ as a criterion to compare the performance of various dispersants.

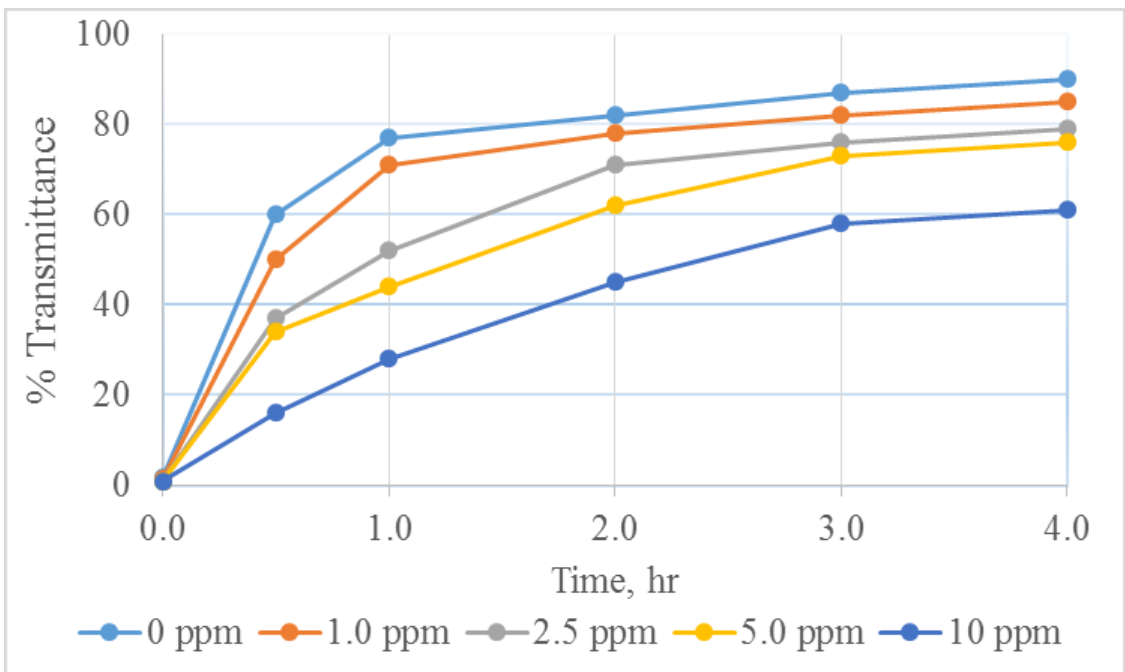

Figure 1. Plots of $\%$ transmittance $v s$. time for HAP dispersion in the presence of varying concentration of CMI-25. 
To study the degree of carboxylation of CMI, a series of experiments was carried in the presence of $10 \mathrm{ppm}$ of CMI-15, CMI-20, and CMI-25, where the number correspond to the degree of carboxylation per monosaccharide monomer unit, and LS as a function of time. Figure 2 shows $\% D$ calculated at $3 \mathrm{hr}$ according to Equation 1 . It is evident that dispersing ability of the CMI increases with degree of carboxylation. For example, $\% D$ values obtained for CMI-15 and CMI-20 are $18 \%$ and $24 \%$, respectively compared to $35 \%$ obtained for CMI-25. Similar trends in CMI performance with increasing degree of carboxylation has been observed for iron oxide dispersion [14], calcium carbonate inhibition, and copper hydroxide stabilization $[15,16]$.

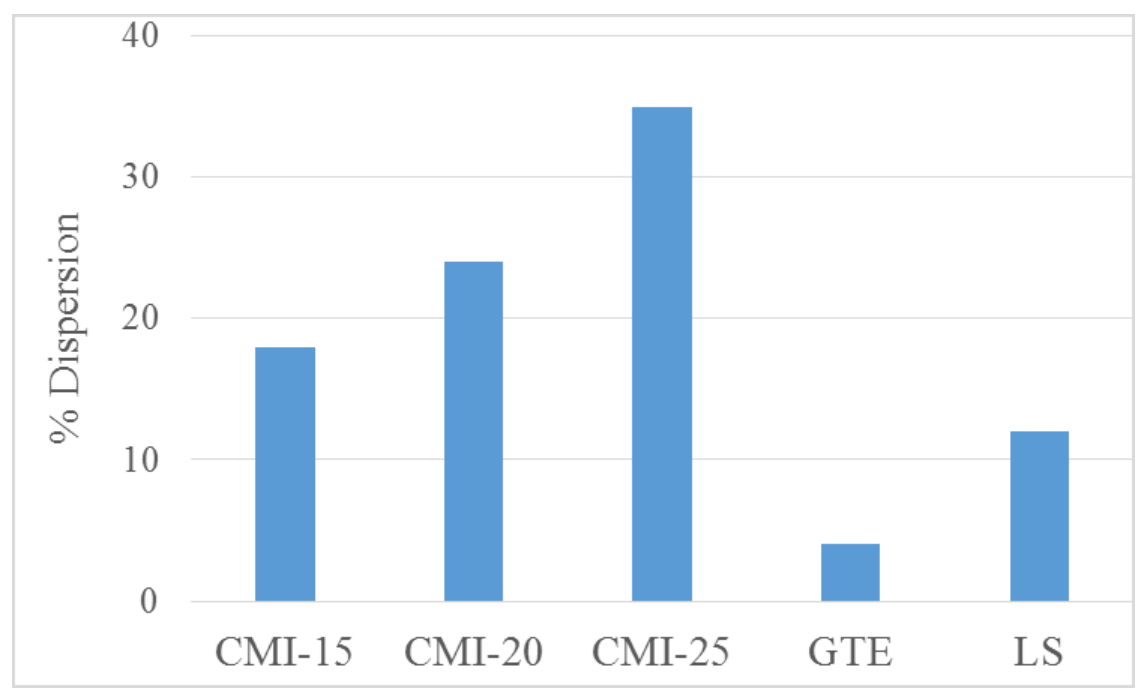

Figure 2. HAP dispersion at $3 \mathrm{hr}$ in the presence of $10 \mathrm{ppm}$ of biopolymers.

Lignosulfonate (LS) are chemically modified biopolymers that are produced during the production of cellulose with the use of sulfites. Both soft and hard woods are used as a raw material during the production of cellulose and lignin. The biopolymer basis of LS is lignin, which is found in wood and other types of plants. LS exhibits dispersive stabilizing, binding, and antifungal properties [17]. Additionally, LS are used in a whole variety of applications including cement additives, dyes, and industrial cleaners, dispersants, and as a filter and binding ceramic tiles. LS contains two functional groups (i.e., phenolic, $-\mathrm{OH}$; sulfonic acid, $-\mathrm{SO}_{3} \mathrm{H}$ ) responsible for surface active properties. In contrast, $\mathrm{CMI}$ is a chemical derivative produced by carboxymethylation of inulin and contains only one functional group (i.e., $-\mathrm{COOH}$ ). The structures of LS and CMI have been reported in earlier studies $[13,18]$.

Using the experimental protocol described earlier, a series of dispersion experiments was carried out in the presence of varying concentration of LS. Figure 2 presents the results on the evaluation of LS with a MW of 2,900 and degree of sulfonation 3.1 as a function of LS concentration. As illustrated in Figure 2 LS shows poor performance 
compared to CMI-25. For example, $\% D$ values obtained in the presence of $10 \mathrm{ppm}$ of LS and CMI-25 are 12 and $35 \%$, respectively. It is worth noting that increasing the LS concentration from $10 \mathrm{ppm}$ to 25 does not show exhibit any significant impact on the performance of LS thus suggesting poor interaction of $-\mathrm{SO}_{3} \mathrm{H}$ group with calcium ions present in HAP. It is interesting to note that whereas LS shows poor performance as HAP dispersant, it has been shown to be a good dispersant for iron oxide, thus suggesting that dispersing property of a polymer depends on the substrate being dispersed [3].

To understand the impact of a phenolic group present in green tea extract (GTE), dispersion experiments were conducted in the presence of 10 of GTE. It is evident from Figure 2 that GTE is an ineffective HAP dispersant thus suggesting that phenolic groups present in GTE shows poor interactions with calcium ions in HAP. It is worth pointing out that whereas GTE is a poor HAP dispersant, it has been found to affect the morphology of calcium carbonate crystals [19].

\section{Performance of Synthetic Polymers}

During the past three decades, a wide variety of polymers containing different functional groups have been developed and are currently used to control scale, stabilize metal ions, and disperse suspended matter in aqueous systems. It is generally agreed that polymer performance as scale inhibitors and/or dispersants depends upon various factors including molecular weight, ionic charge of the functional group, polymerization solvent, type and amount of monomers, etc. [20].

Figure 3 shows $\% D$ data calculated according to Equation 1 for $3 \mathrm{hr}$, as a function of PA (polyacrylic acid, MW 3,000) concentration. It can be seen that PA performance as a HAP dispersant depends on polymer concentration. For example, PA at $1.0 \mathrm{ppm}$ shows poor performance $(<5 \% D)$. However, increasing the PA concentration twofold (i.e., from 2.5 to $5.0 \mathrm{ppm}$ ) results in a significant increase in $\% D$ values (from 13 to $20 \%$ ) and further increase in PA concentration to $10 \mathrm{ppm}$ yields $42 \%$, a $c a$. twofold increase in $\% D$ value. It is worth noting that a trend in PA concentration $v s . \% D$ profiles similar to that observed in the present study has been reported for iron oxide and clay [3,5].

In recent years, the effect of MW on the performance of polymers as scale inhibitors and dispersants has been the subject of numerous investigations. Amjad in studies on the evaluation of PA, in controlling the precipitation of $\mathrm{BaSO}_{4}$ [21], $\mathrm{CaSO}_{4} \cdot 2 \mathrm{H}_{2} \mathrm{O}$ [22], $\mathrm{CaHPO}_{4} \cdot 2 \mathrm{H}_{2} \mathrm{O}$ [23], and iron oxide dispersants [3] reported that polymer MW plays an important role in the inhibition of various scales and dispersing iron oxide. Results of these studies indicate that especially for PA, the optimum performance is obtained with $\sim 2,000$. For copolymers, however, slightly higher MW $(5,000-10,000)$ gives optimum performance. Further, the optimum MW is strongly dependent on the type and amount of comonomers present in the copolymer [24]. The effect of MW on the performance of PA was also investigated by conducting several experiments in the presence of $10 \mathrm{ppm}$ of 
poly(acrylic acid) with varying MW. Results presented in Figure 4 clearly show that HAP dispersion decreases with increase in MW. For example, $\% D$ values obtained in the presence of PA (MW 3k) and MW 60k, are $41 \%$ and $10 \%$, respectively.

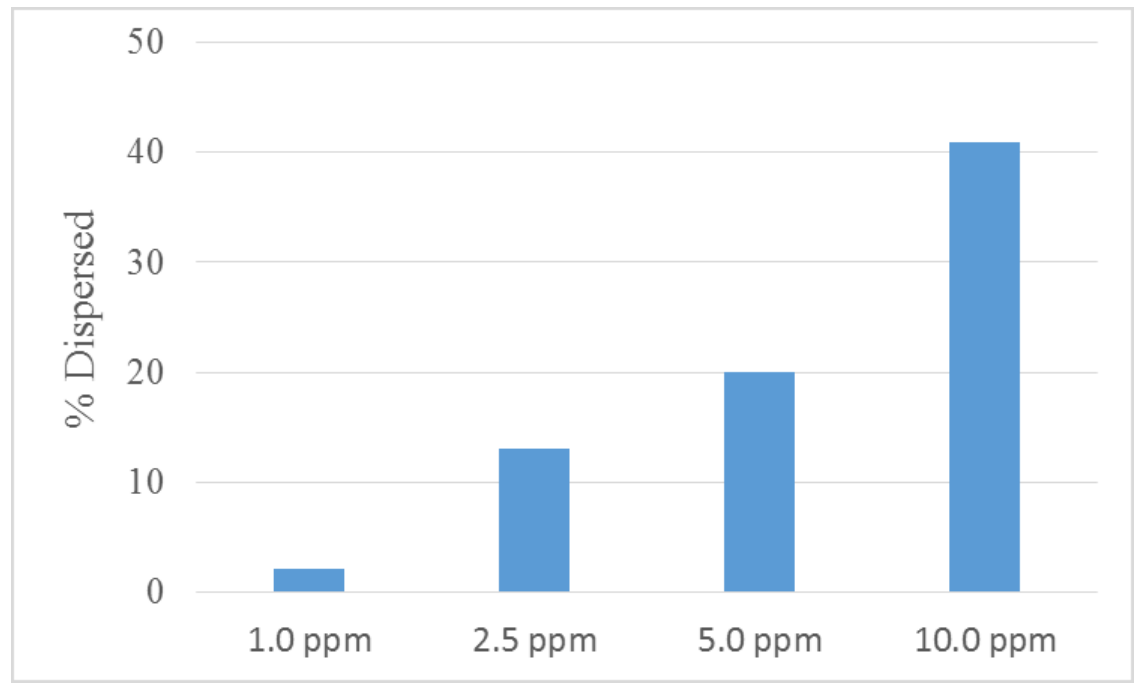

Figure 3. HAP dispersion at $3 \mathrm{hr}$ in the presence of varying concentration of poly(acrylic acid), PA.

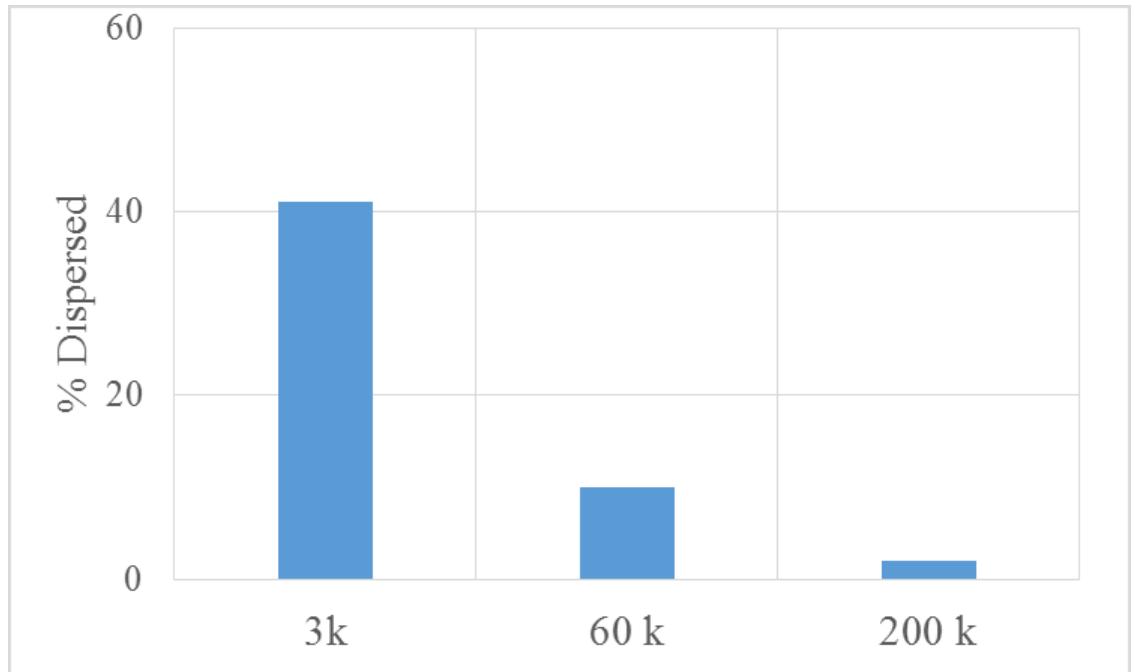

Figure 4. HAP dispersion at $3 \mathrm{hr}$ in the presence of $10 \mathrm{ppm}$ of poly(acrylic acid) of varying molecular weight $(k=1,000)$.

To study the impact of functional groups present in the polymer, a series of dispersion experiments was carried out under similar experimental conditions ( $10 \mathrm{ppm}$ polymer, $3 \mathrm{hr}$ ). It is evident from the data presented in Figure 5 that polymer performance strongly depends on polymer architecture. It can be seen that among the homopolymers containing one functional group $(-\mathrm{COOH})$ i.e., poly(maleic acid), PM; poly(aspartic acid), PAS, 
poly(methacrylic acid), PMA, tested, PA shows the best performance as HAP dispersant. It is interesting to note that polymers that are devoid of $-\mathrm{COOH}$ groups such as poly(vinylpyrrolidone), PV; and poly(diallyldimethyl ammonium chloride), PDA, are ineffective HAP dispersants. For example, $\% D$ values obtained in the presence of $10 \mathrm{ppm}$ PV and PDA are $<5 \%$ compared to $41 \%$ obtained for PA. It is worth noting that whereas PDA shows poor performance as HAP dispersant, PDA has been reported to be a good inhibitor for silica scale [25]. On the other hand, PA shows good dispersancy activity for HAP, but it is known to be ineffective as silica inhibitor. Thus, the performance of a polymer depends on the scale being inhibited. Figure 5 also shows the performance of a copolymer of acrylic acid:2-acrylamido-2-methylpropane sulfonic acid:sulfonated styrene, PSS. It can be seen that partly replacing $-\mathrm{COOH}$ in PA with $-\mathrm{SO}_{3} \mathrm{H}$ containing monomers results in a significant improvement in polymer performance. For example, $\% D$ values obtained in the presence of $10 \mathrm{ppm}$ of PSS are $65 \%$ compared to $41 \%$ for PA.

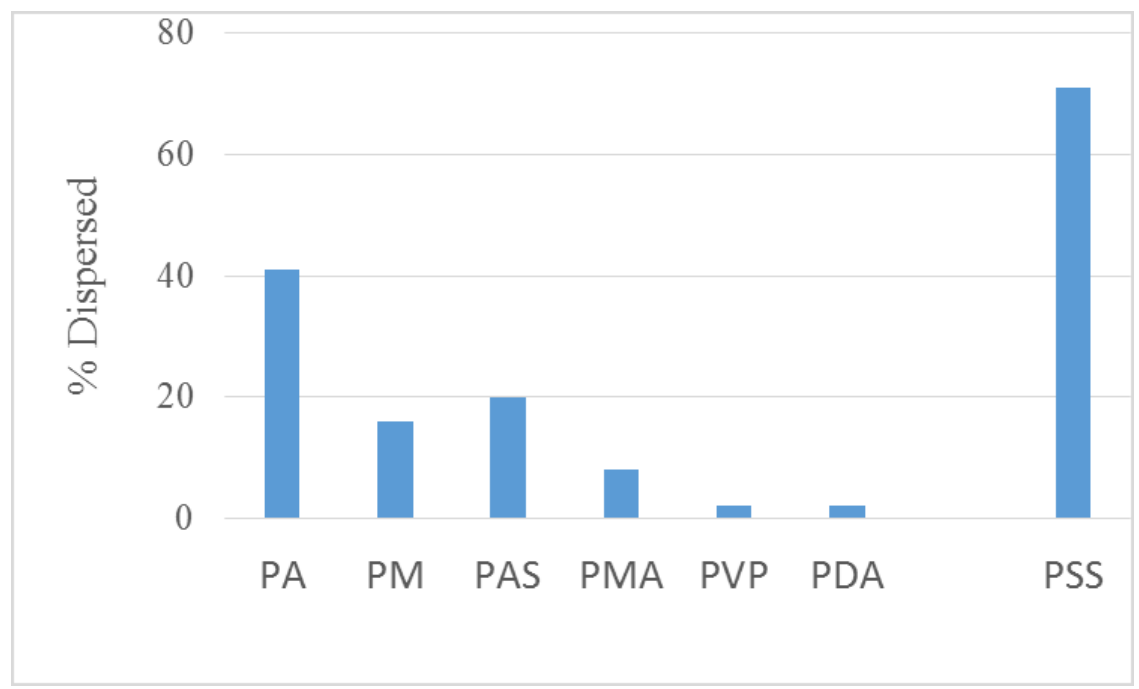

Figure 5. HAP dispersion at $3 \mathrm{hr}$ in the presence of $10 \mathrm{ppm}$ of various homopolymers.

\section{Surfactant performance}

Recently, El-Shall et al. [26] have examined the effect of a commercial non-ionic surfactant on the filterability of gypsum crystals. It was reported that the presence of a small amount of soluble impurities alters the growth rate and habit of formed crystals. Mahmoud et al. [27] in their study on the evaluation of surfactants reported that whereas cetyltrimethylammonium bromide (CTAB) decreased the induction time and increased the growth efficiency, while addition of sodium dodecyl sulfate (SDS) increased the induction time and decreased the growth efficiency compared with the baseline (without additives).

To examine and compare the performance of surfactants i.e., sodium lauryl sulfate (SLS), sodium xylene sulfonate (SXS), octylphenol ethoxylate (OPE), cocamidoprpyl betaine (CAPB) and cetyltrimethyl ammonium chloride (CTAC), a series of dispersion 
experiments was carried out under similar experimental conditions. Results presented in Figure 6 show that all surfactants (i.e., cationic, anionic, amphoteric, and non-ionic) compared to poly(acrylic acid), PA, are ineffective HAP dispersants. For example, $\% D$ values obtained in the presence of $5 \mathrm{ppm}$ are $<5 \%$ compared to $20 \%$ obtained in the presence of PA, respectively. As illustrated in Figure 6, increasing the surfactants concentration by twofold i.e., from 5.0 to $10 \mathrm{ppm}$, does not show any significant improvement in surfactant performance. It is worth noting that whereas polymers containing $-\mathrm{COOH}$ and $-\mathrm{SO}_{3} \mathrm{H}$ groups (PSS, Figure 5) show excellent performance, the presence of these groups in surfactants does not show any efficacy as HAP dispersants. The observed difference in performance between polymers and surfactants may be attributed to poor adsorption and/or molecular weights. It is interesting to note similar performance trend was also observed in dispersion of iron oxide by surfactants and polymers [28].

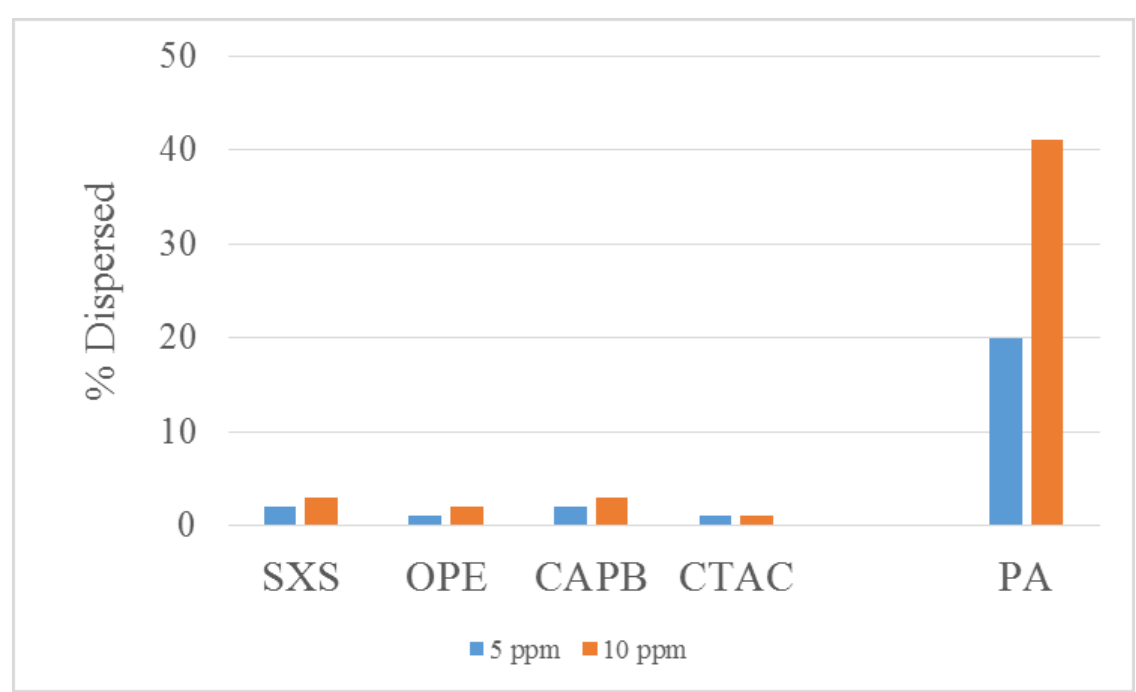

Figure 6. HAP dispersion at $3 \mathrm{hr}$ in the presence of 5 and $10 \mathrm{ppm}$ of various surfactants and PA.

\section{Effect of surfactants on polymers performance}

In view of above results (Figure 5) that anionic polymers exhibit marked dispersing property, several experiments were carried out to study the impact of surfactants on the performance of copolymer, PSS. Results presented in Figure 7 show that under similar experimental conditions, addition of $5.0 \mathrm{ppm}$ of ionic, non-ionic, and amphoteric surfactants i.e., SLS, SXS, OPE, CAPB does not exhibit any significant influence on the performance of PSS. However, as noted in Figure 7 addition of $5.0 \mathrm{ppm}$ of CTAC exhibits antagonistic effect on the performance of PSS. For example, $\% D$ values obtained in the presence of $10 \mathrm{ppm}$ of PSS are $71 \%$ compared to $58 \%$ obtained in the presence of $10.0 \mathrm{ppm}$ of PSS and $5.0 \mathrm{ppm}$ CTAC. The negative influence shown by CTAC on PSS may be attributed to poor compatibility of cationic surfactant with anionic polymer, PSS. 


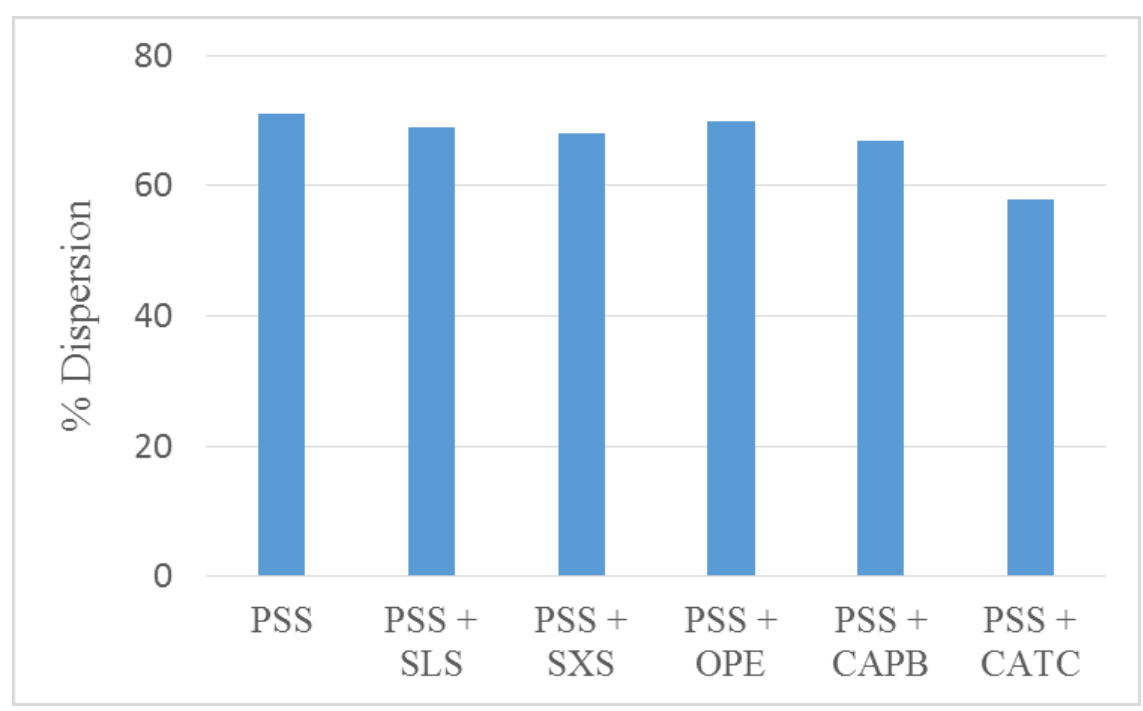

Figure 7. HAP dispersion at $3 \mathrm{hr}$ in the presence of copolymer (PSS) and copolymer/surfactant blends.

\section{Effect of cationic polymer on polymers performance}

Cationic polymers are extremely important materials used to clarify the wastewaters via processes known as coagulation and flocculation [29]. Wastewaters requiring treatment come from a wide range of sources including food processing, industrial manufacturing, and wastewater generated from during the extraction and refining of petroleum. Cationic polymers commonly used to treat wastewater include homopolymer of polyethylenediaimine, diallyldimethylammonium chloride, and copolymers of acrylic acid:acrylamide. These polymers neutralize the charge of the colloidal particles in the water to form large particles. In most cases these large particles (flocks) are removed via settling in a clarifier and are recollected as sludge. Occasionally, clarifier upsets cause the residual polymer to carryover. It has been reported that low levels of cationic polymer, if present in the recirculating water, can interact with the highly anionic charged polymers commonly used as scale control agents and dispersant in water treatment formulations [30].

The results of HAP dispersancy experiments carried out in the presence of varying concentration of cationic polymer, diallyldimethyl ammonium chloride, PDA and $10.0 \mathrm{ppm}$ of copolymer containing $-\mathrm{COOH}$ and $-\mathrm{SO}_{3} \mathrm{H}$ (PSS), are presented in Figure 8. It can be seen that addition of small concentration i.e., $2.50 \mathrm{ppm}$ of DAC exhibits antagonistic effect on the performance of PSS. For example, $\% D$ values obtained in the presence of $10.0 \mathrm{ppm}$ of PSS and $2.50 \mathrm{ppm}$ of DAC are $50 \%$ compared to $71 \%$ obtained in the presence of $10.0 \mathrm{ppm}$ of PSS and $0 \mathrm{ppm}$ of DAC, a reduction of $\sim 20 \%$ in $\% D$ values. As illustrated in Figure 8 increasing the DAC concentration by four fold i.e., from $2.5 \mathrm{ppm}$ to $10.0 \mathrm{ppm}$, results in further decrease in $\% D$ value (i.e., from $50 \%$ to $18 \%$ ). Figure 8 also presents results on the effect of varying concentration of CTAC (cationic surfactant). It can 
be seen that CTAC also exhibits antagonistic effect on PSS performance but not as pronounced as observed for PDA.

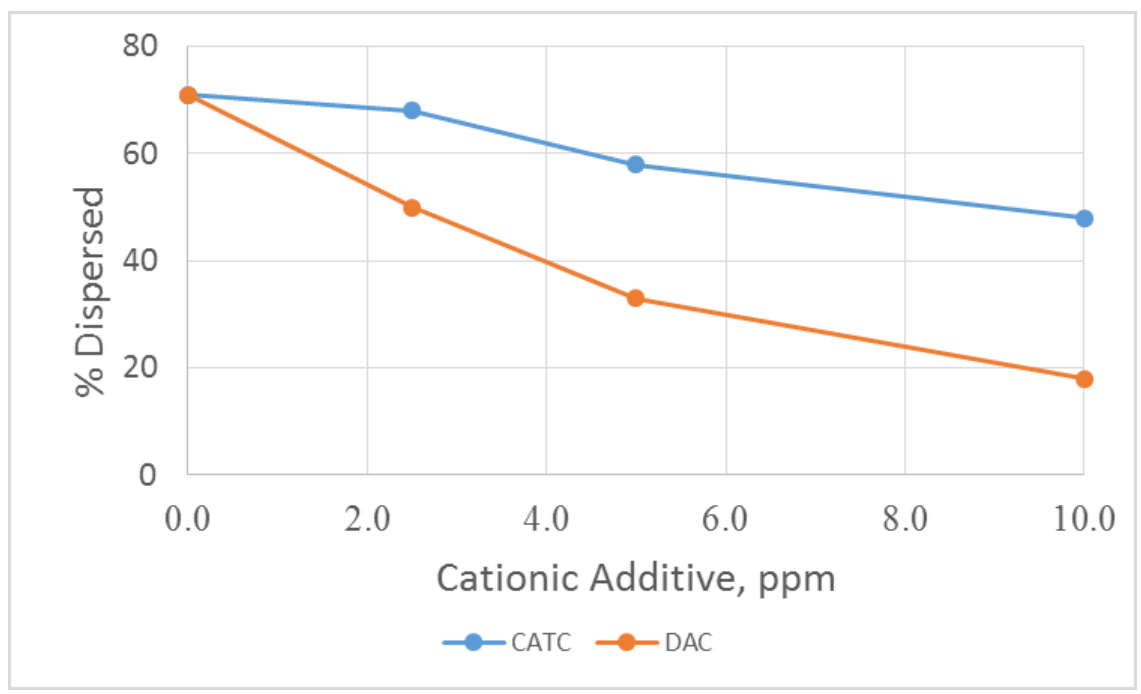

Figure 8. HAP dispersion at $3 \mathrm{hr}$ in the presence of copolymer (PSS) and varying concentration of cationic surfactant and cationic polymer.

\section{Characterization of Dispersed HAP Particles}

Figure 9 (A to F) presents photographs of HAP dispersions in the absence and presence of $10 \mathrm{ppm}$ of CMI-25, poly(acrylic acid), PA, and acrylic acid-based copolymer (PSS) containing sulfonic acid groups. It can be seen (Figure 9A, B, C, D) at T=0 hr that all dispersions show low \% transmittance $(<2 \%)$ or greater dispersion. In Figure $(9$ E, F, G, H) photographs of dispersions are shown at $3 \mathrm{hr}$. It is evident that in the absence of polymer (Figure 9 E) most of HAP particles are settled at the bottom of the cylinder. The performance of CMI-25 and PA are presented in Figure 9 F, G). As illustrated, CMI-25 compared to PA shows poor dispersancy activity. However, the situation is quite different in the presence of PSS. As may be seen most of HAP particles are effectively dispersed by PSS (Figure $9 \mathrm{H}$ ). The dispersion property as illustrated by PSS is very desirable as smaller particles will have less potential of settling on the equipment surfaces.

\section{Summary}

This study suggests the following conclusions:

- Dispersion of HAP by polymer increases with increasing polymer concentration and polymer contact time with HAP particles.

- Polymers containing mono-functional group (i.e., $-\mathrm{COOH},-\mathrm{SO}_{3} \mathrm{H}$ ) perform poorly compared to copolymer containing di-functional groups.

- Performance of CMI (biopolymer) strongly depends upon the degree of carboxylation. 
- Anionic (negative) and non-ionic (neutral) charge surfactants are ineffective HAP dispersants.

- Cationic additives (i.e., flocculant/coagulant, surfactant) show antagonistic influence on dispersant performance.

- Based on the data presented dispersants can be ranked, in terms of decreasing effectiveness, as follows: Synthetic polymers (i.e., copolymer $>$ homopolymer) $>$ biopolymer.

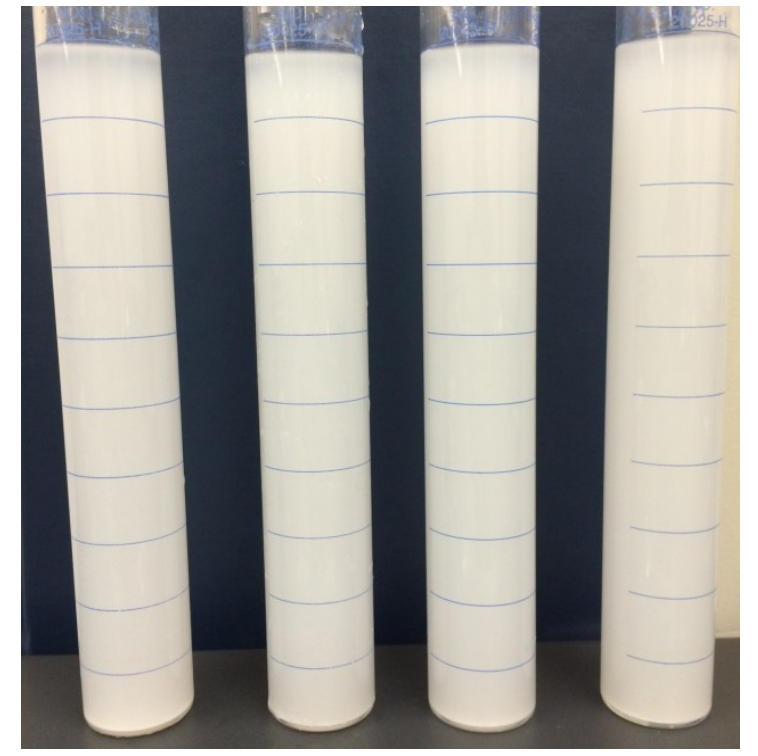

(A)

(B)

(C)

(D)

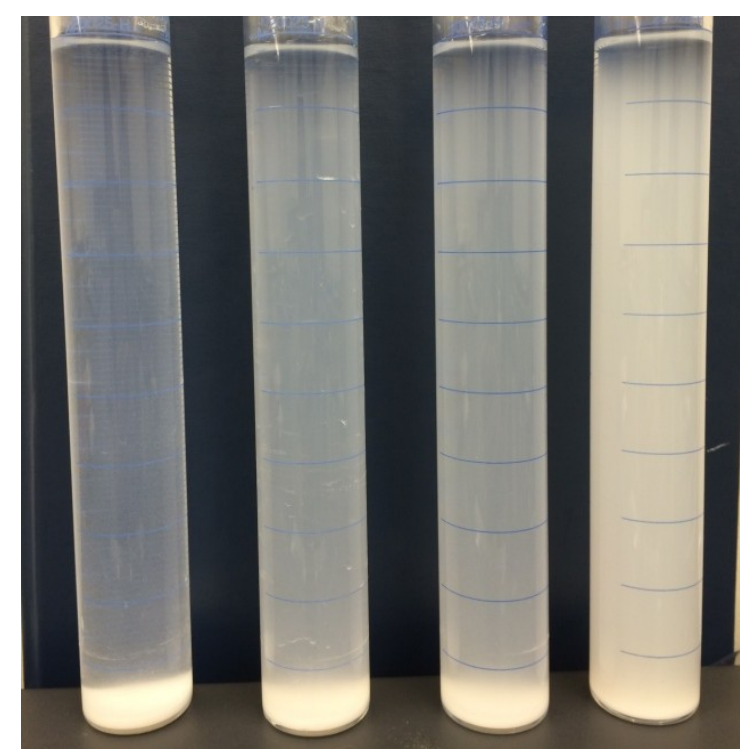

(E)
(F)

(G)
(H)

Figure 9. Dispersion of HAP in the presence of $0 \mathrm{ppm}$ polymer at $0 \mathrm{hr}$ and $3 \mathrm{hr}(\mathrm{A}, \mathrm{E})$; $10 \mathrm{ppm}$ of CMI-25 at $0 \mathrm{hr}$ and $3 \mathrm{hr}(\mathrm{B}, \mathrm{D}) ; 10 \mathrm{ppm}$ of PA at $0 \mathrm{hr}$ and $3 \mathrm{hr}(\mathrm{C}, \mathrm{G})$; and $10 \mathrm{ppm}$ of PSS at $0 \mathrm{hr}$ and $3 \mathrm{hr}(\mathrm{D}, \mathrm{H})$.

\section{Acknowledgement}

The author thanks Walsh University for support to carry out this investigation.

\section{References}

1. Z. Amjad, Langmuir, 1987, 3, 1063.

2. B. Bolto and J. Gregary, Water Res., 2007, 41, 2301.

3. Z. Amjad, Tenside Surfactants Detergents, 1999, 36, no. 1, 50.

4. Z. Amjad and R. Zuhl, paper presented at the Annual Convention and Exposition of Association of Water Technologies, Hollywood, FL, 2009.

5. Z. Amjad and R. Landgraf, Mater. Perform., 2014, 53, no. 2, 44. 
6. L. Dubin and K. E. Fulks, Paper no. 118, CORROSION/84, Houston, Texas, NACE International, 1984.

7. R. Zuhl and Z. Amjad, paper presented at the Annual Convention and Exposition of Association of Water Technologies, Las Vegas, NV, 1993.

8. C. H. Rodriguez, L. H. Lowry, J. F. Scaehorn, J. H. Howell, Surfactants and Detergents, 2001, 4, 1.

9. J. Caelles, F. Cornellies, J. Leal, J. Parma and S. Anguera, Cosmetics and Toiletries, 1991, 106, 39.

10. Z. Amjad, Tenside Surfactants Detergents, 2011, 48, no. 1, 53.

11. D. L. Verraest, J. A. Peters, H. van Bekkum and D. M. van Rosmalen, J. Oil Chemists Assoc., 1996, 73, no. 1, 55.

12. K. D. Demadis and I. Leonold, Mater. Perform., 2011, 50, no. 10, 40.

13. E. Akyol, O. Dogan, M. Oner, Mineral Scales in Biological and Industrial Systems, Ch. 4, Ed. Z. Amjad, Boca Raton, FL, 2014.

14. Z. Amjad and D. Guyton, Mater. Perform., 2012, 51, no. 3, 48.

15. Z. Amjad and J. Penn, Mater. Perform., 2014, 53, no. 11, 52.

16. Z. Amjad, Mater. Perform., 2013, 52, no. 3, 50.

17. J. M. Harkin, Lignin and its Uses, USDA Forest Service Research Note, FPL-0206, July 1969.

18. Z. Amjad, in Mineral Scales in Biological and Industrial Systems, Ch. 6, Ed. Z. Amjad, CRC Press, Boca Raton, FL, 2014.

19. Z. Amjad, Tenside Surfactants Detergents, 2006, 43, no. 4, 184.

20. Z. Amjad, R. W. Zuhl and S. Huang, in The Science and Technology of Industrial Water Treatment, Ch. 22, Ed. Z. Amjad, CRC Press, Boca Raton, FL, 2010.

21. Z. Amjad, Water Treatment, 1994, 9, 47.

22. Z. Amjad, J. Colloid Interface Sci., 1988, 123, no. 2, 523.

23. Z. Amjad, Phosphorus Research Bull., 1988, 8, 71.

24. Z. Amjad, in Calcium Phosphates in Biological and Industrial Systems, Ch. 16, Ed. Z. Amjad, Kluwer Academic Publishers, Boston, MA, 1998.

25. Z. Amjad and M. Yorke, US Patent, 4532049, April 09, 1985.

26. H. El-Shall and B. M. Abdel-Aal, Sep. Sci. Technol., 2000, 35, 395. 
27. M. H. Mahmoud, H. M. M. Rashad， I. A. Ibrahim and E. A. Abdel-Aal， J. Colloid Interface Sci., 2004, 270, 99.

28. Z. Amjad, Tenside Surfactants Detergents, 2011, 48, no. 3, 190.

29. L. Jackson, in The Science and Technology of Industrial Water Treatment, Ch. 23, Ed. Z. Amjad, CRC Press, Boca raton, FL, 2010.

30. Z. Amjad, R. Zuhl and J. Zibrida, Mater. Perform., 1997, 3, 32. 